\title{
EVALUATION OF THE APICAL MICROLEAKAGE OF THREE DIFFERENT ROOT-END FILLING MATERIALS
}

\author{
Mai H. Abdelrahman", Mohamed Y. Hassan ${ }^{* *}$ and Sara ElMallah***
}

\begin{abstract}
Background: Attemptsforpreserving endodonticallytreated teethafterrootcanaltreatmentfailure have directed the clinicians to surgical intervention; apicectomies with root end resection followed by placement of root-end filling material. Different techniques are used to assess the quality of the apical seal obtained by root end filling materials. Dye penetration is considered the most popular technique. Objective: this in vitro study aimed to evaluate and compare the apical microleakage of three rootend filling materials.
\end{abstract}

Methods: Twenty one upper incisors were utilized, root canals instrumentation was achieved by ProTaper system. Obturation was conducted by lateral condensation technique using Protaper universal gutta percha points. Teeth were apically resected at an angle of $90^{\circ}$ to the long axis of the root and root end cavities were prepared and filled. The samples were coated with varnish, then were immersed in $2 \%$ methylene blue solution for 24 hours. Roots were then sectioned bucco-lingually in a longitudinal direction. Extent of dye penetration was detected by the use of stereomicroscope.

Results: The highest mean value was recorded in MTA group, followed by Guttaflow bioactive and Endoseal groups, where both almost recorded the same mean values. Tukey's post hoc test revealed no statistically significant difference between the three tested groups.

Conclusion: It can be concluded that; all the three groups showed microleakage and none of the three root-end filling materials was able to achieve perfect apical seal. The result also showed that guttaflow bioactive provides a similar reliable seal compared to MTA Fillapex and Endoseal MTA.

KEYWORDS : Root-end filling materials, dye penetration, microleakage

* Lecturer in Department of Dental Biomaterials, Faculty of Dentistry, October University of Modern Sciences and Arts, Egypt.

** Lecturer in Department of Endodontics, Faculty of Dentistry, October University for Modern Sciences and Arts, Egypt.

*** Lecturer in Department of Endodontics, Faculty of Dentistry, Fayoum University, Egypt 


\section{INTRODUCTION}

The main goal of root canal treatment is the complete eradication of the present micro-organisms and preventing their future intrusion in the root canal system. Despite the fact of continuous improvement in endodontic techniques and introduction of new materials, the peri-apical pathosis is not always resolved. Consequently, surgical intervention is the only option left to preserve the tooth ${ }^{(1,2,3)}$.

Surgical endodontic therapy is a series of steps starting by exposing the involved apex followed by resecting of the apical end of the root, then retroclass I cavity is prepared and root end filling material is inserted ${ }^{(3)}$. Root-end filling material intends to achieve an apical hermetic tight seal preventing the leakage of bacteria and bacterial products from the root canal to the periapical tissues ${ }^{(2)}$.

Idealistically root-end filling material should be easily manipulated, radiopaque, dimensionally stable, nonabsorbable, nontoxic, biocompatible, insoluble in tissue fluids, bio-inductive combined with its efficient adherence to the dentin of the prepared cavity, thus preventing microleakage and establishing a tight seal ${ }^{(1,3,4)}$.

A number of root end fillings are currently marketed, mineral trioxide aggregate (MTA) based sealers have proved outstanding biological properties, both in the laboratory and in-vitro studies. MTA Fillapex ${ }^{\circledR}$ has been introduced; it helps in maintaining an alkaline $\mathrm{pH}$ by the continuous release of calcium ions thus initiating an antibacterial activity. MTA Fillapex ${ }^{\circledR}$ is characterized by its homogenous consistency and high flow rate which might be attributed to its composition "MTA powders and salicylate resins", with high resin/MTA ratio ${ }^{(5)}$. Moreover, MTA Fillapex ${ }^{\circledR}$ is paste/paste material marketed in auto mix double syringes or tubes with nanoparticles incorporated in its composition resulting in a homogeneous mix and enhanced flow ${ }^{(6)}$. This is combined with its excellent sealing ability as claimed by the manufacturers ${ }^{(7,8)}$.
Endoseal MTA is one of the pozzolan cements. Pozzolan is a siliceous material that necessitates the presence of moisture in order to react with calcium hydroxide forming compounds with adhesive properties and achieving complete setting. Endoseal MTA is a premixed, creamy, injectable whitish hydraulic sealer characterized by a faster setting time than other MTA products due to the -extreme fineness of the silica particles allowing its deep penetration into narrow root canal. Manufacturers also claim that Endoseal MTA exhibits low cytotoxicity, improved physical properties and bioactivity, suggesting its use either as a root canal sealer or as a root canal filling material ${ }^{(9-11)}$.

Recently, guttaflow bioactive sealer has been introduced, which merges the properties of both; sealer and gutta-percha. Manufacturers claim that it exhibit a excellent sealing ability and adaptability to the root canal walls resulting from its high flow combined with its expansion during setting ${ }^{(12)}$.

The quality of apical sealing of root end filling materials is evaluated in vitro by the apical penetration which resembles in vivo to the degree of microleakage. Many techniques are postulated to detect the degree of leakage of root end filling materials; radioisotope penetration, degree of dye penetration, fluid filtration techniques, electrochemical methods, bacterial penetration and scanning electron microscopy ${ }^{(1,3)}$. Dye penetration is considered the most popular technique, different dyes can be utilized including India ink, basic fuchsin, silver nitrate, methylene blue and Rhodamine $\mathrm{B}^{(13,14)}$.

Accordingly, the aim of this in vitro study was to evaluate and compare the apical microleakage of MTA Fillapex, EndoSeal MTA ${ }^{\circledR}$ and Guttaflow $®$ Bioactive when used as a root end filling materials.

\section{MATERIALS}

MTA FillApex (Angelus, Londrina, PR, Brazil), EndoSeal MTA ${ }^{\circledR}$ (Maruchi, Wonju, Korea) and Guttaflow @ Bioactive (Coltene/Whaledent Inc. Switzerland). 


\section{METHODS}

\section{Teeth selection}

Twenty one recently extracted human upper incisors were selected. Teeth were caries free, without calcifications or internal resorption.

\section{Sample preparation}

Crowns were removed at the level of cementenamel junction by a water cooled precision micro saw (IsoMet 4000 micro saw, Buehler, USA.), leaving averagely $15 \mathrm{~mm}$ long root segments. Working lengths for all canals were inspected by a \# K file (Mani, Tochigi, Japan). Root canals instrumentation was achieved by ProTaper universal system (Dentsply Maillefer, Ballaigues, Switzerland) starting by ; Sx, followed by S1, S2 in a brushing motion, followed by F1,F2 F3,F4 and finally F5 in a non brushing motion, apical patency was checked using the patency file between every file and the other. Irrigation during instrumentation was done with $5 \mathrm{ml}$ of $25 \% \mathrm{NaOCl}$ solution.

Canals were then obturated with gutta percha by lateral condensation technique. Radiographs for the obturated roots were taken to confirm the quality of obturation and composite resin was used for sealing the access cavities. The teeth were then stored in saline for 1 week. An apical $3 \mathrm{~mm}$ from the end of the root was sectioned at $90^{\circ}$ to the long axis of the tooth using crosscut fissure bur and high speed hand piece with water coolant. Then, a 3-mm depth, rootend cavity was prepared in the remaining part of the by using ultrasonic scaler (Wood Pecker, UDS-E LED, made in China) (Power first grade) and ultrasonic tips UE1 (Wood Pecker, made in china) ${ }^{(3,14,15)}$. The samples $(n=21)$ were randomly divided into three groups according to the type of root end filling material used.

\section{Group 1: Guttaflow bioactive}

Group 2: Endoseal MTA

Group 3: MTA Fillapex
Each investigated material was manipulated according to the manufacturer's instructions and the prepared cavities were filled with its corresponding material in the group. The specimens were then coated with 3 coats of nail varnish except $1 \mathrm{~mm}$ from the apex and were allowed to dry ${ }^{(3,14,15)}$.

The samples were immersed in $2 \%$ methylene blue solution for 24 hours. After removal from the dye solution, samples were washed under running water and the nail varnish was removed away from the root surface using a scalpel. Roots were then sectioned bucco-lingually in a longitudinal direction using Isomet 4000 microsaw (Buehler USA) with diamond disc $0.3 \mathrm{~mm}$ thickness (Buehler USA). The dye penetration was detected for each sample from the apex to the most coronal extent of the dye penetration by using Stereomicroscope (Nikon MA 100 Japan) image analysis by Omnimete software Buehler ${ }^{(15,16)}$.

\section{Statistical analysis}

Data management and statistical analysis were performed using the Statistical Package for Social Sciences (SPSS) version 18. Numerical data were summarized using mean, standard deviations, standard error, minimum, maximum and confidence intervals. Data were explored for normality by checking the data distribution and using Kolmogorov-Smirnov and Shapiro-Wilk tests. Data were normally distributed and were compared using one way analysis of variance (ANOVA) test. All p-values are two-sided. P-values $\leq 0.05$ were considered significant.

\section{RESULTS}

Despite the highest mean value was recorded in MTA group, followed by Guttaflow bioactive and Endoseal groups, where both almost recorded the same mean values. Tukey's post hoc test revealed no statistically significant difference-among the three tested groups $(\mathrm{p}=0.745)$, this is shown in (tables 1 and 2, fig.1) 
TABLE (1): Descriptive statistics of microleakge ( $\boldsymbol{\mu} \mathbf{m})$ and comparison between the tested groups.

\begin{tabular}{|c|c|c|c|c|c|c|c|c|c|}
\hline & \multirow[t]{2}{*}{ Mean } & \multirow[t]{2}{*}{ Std. Dev. } & \multirow[t]{2}{*}{ Std. error } & \multicolumn{2}{|c|}{$\begin{array}{c}\text { 95\% Confidence Interval for } \\
\text { Mean }\end{array}$} & \multirow[t]{2}{*}{ Min } & \multirow[t]{2}{*}{ Max } & \multirow[t]{2}{*}{$\mathrm{F}$} & \multirow[t]{2}{*}{$\mathrm{P}$} \\
\hline & & & & Lower bound & Upper bound & & & & \\
\hline Guttaflow & 920.86 & 52.92 & 20.00 & 871.92 & 969.80 & 850.69 & 1010.22 & \multirow{3}{*}{0.3} & \multirow{3}{*}{$0.745^{\mathrm{n}}$} \\
\hline Endoseal & 920.64 & 46.38 & 17.53 & 877.75 & 963.53 & 880.35 & 1008.30 & & \\
\hline MTA & 944.53 & 90.87 & 34.35 & 860.48 & 1028.57 & 821.73 & 1101.30 & & \\
\hline
\end{tabular}

Significance level $p \leq 0.05$, ns=non-significant

TABLE (2): Results of Tukey's HSD for pairwise comparison of microleakge ( $\boldsymbol{\mu} \mathbf{m})$.

\begin{tabular}{|c|c|c|c|c|c|c|}
\hline \multirow{2}{*}{ Group (I) } & Group (J) & Mean difference & Std. error & \multirow{2}{*}{ P value } & \multicolumn{2}{|c|}{$95 \%$ Confidence Interval for Mean } \\
\cline { 3 - 7 } & & & & & Lower bound & Lower bound \\
\hline \multirow{2}{*}{ Gutta-flow } & Endoseal & 0.22 & 35.47 & 1.00 & -90.30 & 90.74 \\
\cline { 2 - 7 } & MTA & -23.67 & 35.47 & 0.79 & -114.19 & 66.85 \\
\hline \multirow{2}{*}{ Endoseal } & Guttaflow & -0.22 & 35.47 & 1.00 & -90.74 & 90.30 \\
\cline { 2 - 7 } & MTA & -23.89 & 35.47 & 0.78 & -114.41 & 66.63 \\
\hline \multirow{2}{*}{ MTA } & Guttaflow & 23.67 & 35.47 & 0.79 & -66.85 & 114.19 \\
\cline { 2 - 7 } & Endoseal & 23.89 & 35.47 & 0.78 & -66.63 & 114.41 \\
\hline
\end{tabular}

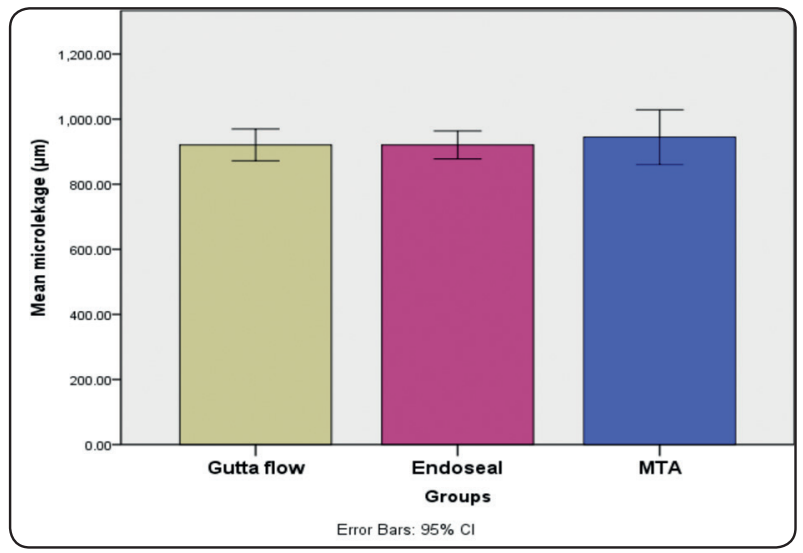

Fig. (1) Bar chart illustrating mean microleakge $(\mu \mathrm{m})$ in the three tested groups

\section{DISCUSSION}

Attempts for preserving endodontically treated teeth after root canal treatment failure have directed the clinicians for surgical intervention; root end resection and root end cavity preparation followed by followed by placement of root-end filling material $^{(1)}$.

One of the key factors for the success of any rootend filling material is its ability to create an efficient barrier between the root end filling material and the periapical tissues, in addition to its biocompitability and handling properties ${ }^{(1,2,14)}$.

Different root end filling materials are commercially available; each of them shows some 
advantages and disadvantages.MTA have been under spot during the past years proving their good physical properties combined with their bioactivity ${ }^{(1,15,17)}$.

Endoseal MTA is considered as a MTA-derived material; consequently its components are like to those of white mineral trioxides aggregates. Accordingly, it is expected to attain physical and biological properties comparable to other MTAderived materials ${ }^{(18)}$.

GuttaFlow bioactive is a silicone-based, coldfilling sealer containing gutta-percha powder and bioactive glass, this combination allowed formation of hydroxyapatite crystals as claimed by the manufacturer ${ }^{(19)}$.

Roots were instrumented by Protaper universal system for time saving and better standardization of instrumentation ${ }^{(20)}$. Quality of the apical seal obtained by root end filling materials has been assessed by different techniques, all of which have some drawbacks ${ }^{(3)}$.

Dye penetration test is the most commonly used test, this popularity comes from its simplicity and reliability for assessment of microleakage of rootend filling materials ${ }^{(6)}$. In current study, methylene blue dye had been favorable for the evaluation of microleakage due to having a molecular size comparable or smaller than that of bacterial products ${ }^{(20)}$.

According to the results of this study; the low microleakage of MTA Fillapex can be attributed to its good flow allowing penetration of the material into the main and lateral root canals and dentinal tubules. The penetration would be facilitated because of the presence of MTA nanoparticles powders and rosins; in addition, MTA capability to form interstitial adherent layer similar to hydroxypatite exhibiting superior marginal adaptation ${ }^{(17)}$.

Nurmeisari et al in 2018(17), compared the sealing ability of MTA Fillapex and an epoxy sealer and their results showed no statistically significant differences between the two tested groups. They explained these comparable results by the presence of calcium silicate hydrate gel produced from the hydration reaction of MTA Fillapex. Calcium silicate hydrate gel is sticky and porous allows binding to gutta percha in addition to its high flowability permitting deep penetration into lateral root canals and dentinal tubules ${ }^{(17)}$.

Khattab SMA et al in $2013^{(2)}$,reported that MTA had an excellent marginal adaptation to dentinal wall with no gaps concluding that MTA adequately seals the interface.

Endoseal MTA exhibited the lowest mean value of microleakage than that of MTA Fillapex but with no statistically significant difference. Endoseal MTA is composed of silica particles with an extremely fine size in the pozzolan cement ${ }^{(11)}$. Analysis of its surface morphology by the aid of scanning electron microscope revealed that Endoseal MTA contain particles of 200 to $400 \mathrm{~nm}$ in size ${ }^{(21)}$. Endoseal MTA is a premixed material supplied in syringe, it is characterized by low mean particle size of $1.5 \mu \mathrm{m}$ that does not impede high flowability and consequently its improved penetration into the lateral and accessory canals ${ }^{(22)}$. Inaddition its documented significant setting expansion ${ }^{(23)}$, contribute for its good sealing ability. This was in accordance with Kim $M$ et al in $2017^{(11)}$.

Dastorani M et al in 2020(18), evaluated and compared the bacterial microleakage of Pro-Root MTA and Endoseal MTA sealers. Their results showed that there was no significant difference between the two tested sealers. They concluded that; although the two tested sealers had the same microleakage, treatment success can be improved by the use of Endoseal MTA due to its easier application and lower technique sensitivity.

While, results of guttaflow bioactive sealer showed mean value lower than that of MTA Fillapex and almost the same as that recorded by 
Endoseal MTAs. This might be explained by the fact that guttaflow bioactive contains both the sealer and a very fine gutta percha powder resulting in the production of excellent flow properties of this guttapercha/ sealer for the first time. The expansion of guttaflow bioactive sealer on setting (24), and close adaptation of gutta percha cone against the instrumented canal wall may enhance its sealing ability, this was supported by Lee SH et al in 2020 and Priyank $H$ et al in $2017^{(19,25)}$.

\section{CONCLUSION}

Within the limitations of the current study, it can be concluded that; all the three investigated groups showed comparable microleakage and none of the three root-end filling materials was able to achieve perfect hermetic apical seal. The results also showed that the newly introduced guttaflow bioactive root end filling material provides a similar reliable seal compared to that of both MTA Fillapex and Endoseal MTA.

\section{REFERENCES}

1. Abd Elhamid HM and Abdel-Aziz MS. marginal adaptation and sealing ability evaluation of new nano materials as root end filling material (an invitro study). EDJ. 2020; 66:1829-1836.

2. Khattab SMA, Kattaia MA and Galal K. A comparative study of the sealing ability of a new resin bonded material and mineral trioxide aggregate as root-end filling materials an in-vitro study. CDJ. 2013;29(1): 469-476.

3. Desai N, Rajeev S, Sahana S, Jayalakshmi KB, Hemalatha B, Sivaji K, Kumar RV, Krishna VV, Savitri D and Singh GP. In vitro comparative evaluation of apical microleakage with three different root-end filling materials. International Journal of Applied Dental Sciences 2016; 2(3): 29-32.

4. Fogel HM and Peikoff MD. Microleakage of root-end filling materials. J. Endod. 2001;27(7):456-458.

5. Lee JK, Kwak SW, Ha JH, Lee WC and Kim HC. Physicochemical properties of epoxy resin-based and bioceramic-based root canal sealers. Bioinorg.Chem. Appl. 2017; (1):1-8.
6. MTA Fillapex - Endodontic sealer. Scientific Profile. http:// www.angelusdental.com/img/arquivos/mta_fillapex_ technical_profile.

7. Elsherief S, Elmarsafy SM and Youssef A. Bacterial leakage analysis of root canal obturated using single cone technique with three different root canal sealers and three different coronal restorative materials (in-vitro study). EDJ. 2019; 65(3): 2625:2633.

8. Nurmeisari, Djauharie $\mathrm{N}$ and Indrawati D. Comparison of sealing ability in the apical third of tooth root canals after post preparation and obturation with MTA sealer and epoxy sealer. J. Phys. Conf. Ser. 2018; 1073(6):062018.

9. Kim H, Kim Y, Nam S, Taeyub K and Kim H. evaluation of sealing effect and working time of root canal filling MTA materials. J Korean Acad Pediatr Dent. 2016; 43(2):129-136

10. Rehan AK. Biocompatibility and osteogenic potential of the new bioceramic endodontic material endoseal MTA. EDJ.2019; 65(2): 1577-1583.

11. Kim M,Park H, Lee J and Seo H. Microleakage assessment of a pozzolan cement-based mineral trioxide aggregate root canal sealer. J Korean Acad Pediatr Dent.2017; 44(1): 20-27.

12. Abdelrahman MH, Khalil MM and El-Mallah S. Physical properties of an endodontic sealer containing calcium silicate. EDJ. 2020; 66(3):1649-1655

13. Pandey R, Dixit N, Dixit KK, Roy S, Gaba C and Goyal C. Comparative evaluation of microleakage of mineral trioxide aggregate and Geristore root-end filling materials in different environments: An in vitro study. J Cons. Dent. 2018;21(3):328-332.

14. Saini D, Nadig G and Saini R. A comparative analysis of microleakage of three root end filling materials - an in vitro study. Archives of Orofacial Sciences. 2008; 3(2):43-47.

15. Xavier CB, Weismann R, Oliveira MG, Demarco FFand Pozza DH. Root-end filling materials: apical microleakage and marginal adaptation. J Endod. 2005;31(7):539-42.

16. Desouky AA, Negm MM and Ali MM. sealability of different root canal nanosealers: nano calcium hydroxide and nano bioactive glass. Open Dent. J. 2019, 13, 308-315.

17. Nurmeisari, Djauharie $\mathrm{N}$ and Indrawati D. Comparison of sealing ability in the apical third of tooth root canals after post preparation and obturation with MTA sealer and epoxy sealer. J. Phys. Conf. Ser. 2018; 1073(6):062018. 
18. Dastorani M, Shourvarzi B, Nojoumi F and Ajami M. Comparison of bacterial microleakage of endoseal MTA sealer and Pro-Root MTA in root perforation. J Dent Shiraz Univ Med Scien. 2020; 1-7.

19. Lee SH,Oh S,Al-GhamdiAS,3 MandorahAO,KumKY and Chang SW. Sealing ability of AH Plus and GuttaFlow Bioseal.Bioinorg.Chem. Appl. 2020;10.1155/2020/8892561.

20. Desouky AA, Negm MM and Ali MM. sealability of different root canal nanosealers: nano calcium hydroxide and nano bioactive glass. Open Dent. J. 2019, 13, 308-315.

21. Jo SB, Kim HK, Lee HN , Kim YJ, Patel KD, Knowles JC, Lee JH and Song M. Physical properties and biofunctionalities of bioactive root canal sealers in vitro. Nanomaterials. 2020 .

22. Saba AA and ElAsfouri HA. Fracture resistance of endodontically treated teeth obturated with different root canal sealers (in vitro study). EDJ. 2019; 65: 1567:1575.

23. Lim EU, Park YB, Kwon YS, Shon WJ, Lee KW and Min KS. Physical properties and biocompatibility of an injectable calcium-silicate-based root canal sealer: in vitro and in vivo study. BMC Oral Health. 2015; 15: 129.

24. Dastorani M, Malekpour B, Sobhani MA, Alemrajabi M, Mahdian A and Malekpour B. Comparison of bacterial microleakage of three bioactive endodontic sealers in simulated underwater diving and aviation conditions. Res. Sq. 2020; 10.21203/rs.3.rs-112668/v1 .

25. Priyank H, Mahalakshmi V and Verma A. Comparative analysis on apical microleakage in root canals obturated with gutta flow, thermafil and regular gutta percha with lateral condensation - a stereomicroscopic study. J Adv Med Dent Scie Res. 2017;5(10):1-6. 